\title{
FATORES DE RISCO ASSOCIADOS AO SEXO EM PACIENTES COM ACIDENTE VASCULAR CEREBRAL
}

\author{
Larissa Mariana Oliveira Santos \\ Graduanda de Enfermagem, Faculdade de Enfermagem - UNICAMP \\ larissa0235@hotmail.com
}

INTRODUÇÃO: O acidente vascular cerebral (AVC) é a segunda principal causa de morte e a primeira causa de incapacidade no mundo. Dentre desse contexto, entender as variáveis que explicam diferenças epidemiológicas na incidência e gravidade do AVC pode ser útil na identificação de grupos específicos com um risco aumentado e nas propostas futuras a serem consideradas como recomendações de prevenção primária e secundária. OBJETIVO: investigar os fatores de risco específicos por sexo em pacientes com acidente vascular cerebral. MÉTODO: Estudo correlacional, transversal, realizado junto a um hospital público e terciário do Brasil, situado na cidade de Campinas-SP, com acompanhamento de pacientes que realizaram atendimento da fase aguda desde outubro de 2017. Foram abordados 110 pacientes e, destes, 47 foram incluídos no estudo. A fonte para coleta de dados foi do tipo primária e secundária. Utilizou-se formulário de coleta de dados com tópicos sobre dados sociodemográficos, fatores de risco e dados do ictus. Aplicou-se estatística descritiva e testes inferenciais, de associação e comparação por meio do SPSS, versão 24.0. O projeto foi encaminhado ao Comitê de Ética em Pesquisa e aprovado com parecer de número: 2.237.107. RESULTADOS: Os fatores de risco ligados ao sexo com maior frequência foram os femininos: gravidez $\geq 3$ (presente em quase $70 \%$ da amostra feminina), menarca $\leq 12$ anos, menopausa $\leq 55$ anos e uso de anticoncepcional (ACO) presentes, cada um, em 43,5\% da amostra. Não houve expressivo registro de mulheres com complicações na gravidez e hipertensão gestacional. Dentre os fatores de risco ligados ao sexo masculino, a disfunção erétil esteve presente em um paciente. Os demais fatores de risco ligados ao sexo masculino, orquiectomia, terapia de privação androgênica e terapia com testosterona, não foram identificados. Não houve associação estatística entre as variáveis sociodemográficas e clínicas com os fatores de risco específicos por sexo. CONCLUSÃO: Os fatores de risco ligados ao sexo feminino mostraram-se mais frequentes dentre as pacientes que foram 
acometidas pelo AVC. Estudos de investigação de novos fatores de risco em pacientes com AVC são fundamentais, principalmente ao se considerar a mudança nos perfis epidemiológicos.

Palavras-chave: Acidente vascular cerebral. Fatores de risco. Diagnóstico. 